\title{
Obstructive sleep apnoea: longer respiratory event lengths in patients with heart failure
}

\author{
Christina Efken, Thomas Bitter, Natalie Prib, Dieter Horstkotte and \\ Olaf Oldenburg
}

ABSTRACT: This study investigated the effect of heart failure on respiratory patterns in patients with obstructive sleep apnoea (OSA).

39 patients with established OSA (apnoea/hypopnoea index (AHI) $>10$ events $\cdot h^{-1}$ ) and either with heart failure (New York Heart Association (NYHA) class II and III, left ventricular-ejection fraction (LVEF) $\leqslant 40 \%$; $n=26$, age mean \pm SD $67 \pm 9$ years) or without heart failure (LVEF $\geqslant 50 \%, N$ terminal pro-brain naturic peptide $<400 \mathrm{pg} \cdot \mathrm{mL}^{-1} ; \mathrm{n}=13$, age $73 \pm 6$ years) underwent simultaneous right- and left-heart catheterisation within $12 \mathrm{~h}$ of cardiorespiratory polygraphy recording.

Respiratory patterns of OSA were significantly longer in OSA patients with heart failure versus without heart failure, including mean \pm SD cycle length $(46.0 \pm 10.0$ versus $37.8 \pm 10.6 \mathrm{~s} ; \mathrm{p}=\mathbf{0 . 0 2 4})$, ventilation length $(25.4 \pm 6.3$ versus $21.3 \pm 7.1 \mathrm{~s} ; \mathrm{p}=0.044)$, apnoea length $(20.5 \pm 4.9$ versus $16.5 \pm 3.9 \mathrm{~s} ; \mathrm{p}=\mathbf{0 . 0 1 3})$, time-to-peak ventilation $(10.6 \pm 3.0$ versus $8.3 \pm 2.5 \mathrm{sc} ; \mathrm{p}=0.021)$ and circulatory delay $(28.5 \pm 7.5$ versus $22.6 \pm 3.7 \mathrm{~s} ; \mathrm{p}=\mathbf{0 . 0 0 5})$. Positive and robust correlations were found between some of these parameters and the degree of congestion in heart failure: cycle length $(r=0.53 ; p=0.006)$, ventilation length $(r=0.55 ; p=0.004)$ and time-to-peak ventilation $(r=0.47 ; p=0.015)$ all increased with a rise in pulmonary capillary wedge pressure.

Respiratory patterns in OSA appear to be dependent on cardiac function, with an increase in event lengths as cardiac function decreases. In patients with heart failure, some of these events correlate with the degree of pulmonary congestion.

KEYWORDS: Cardiac function, haemodynamics, respiratory patterns, sleep disordered breathing

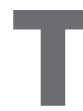
he Sleep Heart Health Study showed that obstructive sleep apnoea (OSA) was associated with an increased risk of incident heart failure [1]. In the presence of heart failure, untreated OSA represents an independent risk factor for the occurrence of malignant ventricular arrhythmias [2] and increased mortality [3], whereas continuous positive airway pressure therapy has been associated with decreased mortality and hospitalisation in patients with heart failure and OSA [4].

Sleep disordered breathing (SDB), and OSA in particular, is a common comorbidity in heart failure patients [5-7]. The prevalence of OSA in patients with heart failure has been reported as being quite high, at $36 \%$ [5]. It is, therefore, becoming increasingly important to understand the potential link between heart failure and OSA, along with the pathophysiology of coexisting OSA and heart failure.

Anatomical predisposition alone is not the only factor contributing to collapsibility of the upper airway. Besides pharyngeal anatomy, fat distribution within the neck, upper airway muscle tone and responsiveness to various stimuli, such as arousals from sleep or sex hormones, have been proposed [8, 9]. In patients with heart failure, an increased loop gain and rostral fluid shift might contribute to altered physiology [10, 11]. Another study has suggested that rostral fluid shift from the periphery towards the neck might cause neck oedema with a resulting increase in upper airway resistance and development of obstruction, providing a unifying concept contributing to the pathogenesis of both OSA and central sleep apnoea (CSA) in patients with heart failure [12].

The occurrence of CSA with Cheyne-Stokes respiration (CSR) in patients with heart failure has been previously investigated in detail [5, 1315]. To briefly summarise, the prevalence and severity of CSA-CSR increases in line with heart failure severity. However, SDB prevalence and severity may decrease when cardiac function improves $[13,15,16]$.
AFFILIATIONS

Dept of Cardiology, HDZ, Heart and Diabetes Centre North RhineWestphalia, Ruhr University Bochum, Bad Oeynhausen, Germany.

\section{CORRESPONDENCE}

0 . Oldenburg

Dept of Cardiology, Heart and

Diabetes Centre North Rhine-

Westphalia, University Hospital

Ruhr University Bochum

Georgstrasse 11

D-32545 Bad Oeynhausen

Germany

E-mail: akleemeyer@hdz-nrw.de

Received:

May 252012

Accepted after revision:

Aug 262012

First published online:

Sept 272012 
The severity of SDB is usually defined by counting the numbers of apnoeas and hypopnoeas per hour of sleep (the apnoea/hypopnoea index (AHI)) [1, 3, 5-7]. However, in heart failure patients with CSA-CSR, an increase in respiratory event lengths may limit the total AHI. Respiratory event lengths may therefore be a more appropriate way to describe the severity of CSA-CSR, and might also be useful as an indicator of cardiac function [14, 17, 18]. A prolonged circulation time (circulatory delay (CD)) in heart failure could alter respiratory feedback mechanisms and cause an increase in the duration of CSA-CSR pattern with prolonged cycle length $(\mathrm{CL})$, ventilation length $(\mathrm{VL})$, apnoea length (AL) and time to peak ventilation (TTPV) $[14,19]$.

We therefore hypothesised that there might be a correlation between heart failure severity and the respiratory pattern in OSA, specifically respiratory event lengths. We investigated the possibility that deterioration of cardiac function with an increase in filling pressures might be linked to an increase in circulation time and changes in respiratory event lengths, such as CL, VL, AL or TTPV.

\section{METHODS}

A total of 380 consecutive patients undergoing simultaneous right- and left-heart catheterisation were prospectively screened for enrolment. The indication for cardiac catheterisation was independent of this study. 40 patients refused to undergo cardiorespiratory polygraphy recordings the next night, 25 polygraphy recordings were of insufficient quality and in five patients the insertion of the cardiac floating catheter failed, respectively the graph for analysis was ambiguous.

Of the remaining 310 patients, 127 (41\%) patients had CSA, 130 $(42 \%)$ had OSA and $53(17 \%)$ had no SDB. Of the 130 OSA patients, 39 had significant OSA (AHI $>10$ events $\cdot h^{-1}$, central respiratory events $<25 \%$ ) and were allocated into the heart failure or non-heart failure group. Patients with pre-treated SDB, decompensated heart failure and/or any moderate-tosevere valvular heart disease (more than a grade II) were excluded from further analysis. 13 of those OSA patients had no clinical signs of heart failure and a preserved left ventricular function (left ventricular ejection fraction (LVEF) $\geqslant 50 \%$, $\mathrm{N}$-terminal pro-brain natriuretic peptide (NT-proBNP) $<400 \mathrm{pg} \cdot \mathrm{mL}^{-1}$ ) [20] and 26 presented with symptomatic but stable heart failure due to impaired left ventricular systolic function (New York Heart Association (NYHA) class II + III, LVEF $\leqslant 40 \%$ ). All patients gave written informed consent to participate in the study, and the protocol was approved by the local ethics committee.

Cardiorespiratory polygraphy recordings were performed as described earlier [5] using a six-channel device (Embletta; Embla, Amsterdam, the Netherlands). Nasal airflow, chest and abdominal efforts, finger pulse oximetry (averaging time $4 \mathrm{~s}$; sampling frequency $3 \mathrm{~Hz}$ ), ECG, snoring and body position were recorded continuously. The temporary loss of one channel, except nasal airflow, was deemed acceptable. Recordings were analysed using Remlogic software (Embla) and reviewed by two separate sleep specialists not involved in the study. Apnoea was defined as a drop in nasal airflow by $\geqslant 90 \%$ of baseline for $\geqslant 90 \%$ of the event's duration and $\geqslant 10 \mathrm{~s}$. This apnoea was specified to be obstructive if there was a continued or increased inspiratory effort throughout the entire period of absent airflow. Hypopnoea was defined as a $\geqslant 50 \%$ fall from baseline in airflow signal for $\geqslant 90 \%$ of the event's duration, $\geqslant 10 \mathrm{~s}$ and $\mathrm{a} \geqslant 3 \%$ desaturation from pre-event baseline [21].

CL was defined as the time from the beginning of an obstructive apnoea to the end of the following ventilation (fig. 1); therefore, CL represents the sum of an obstructive apnoea (AL) and the following ventilation (VL). Time from resumption of airflow to the following peak in airflow was defined as TTPV. CD was the time from the first breath after apnoea to the following nadir of oxygen saturation. Data on respiratory event length shown represent an average of 24 separate measurements obtained throughout the night [14].

\section{Statistics}

Continuous data are expressed as median or mean \pm SD. Statistical analyses were performed using SigmaPlot software version 12.0 (Systat, Erkrath, Germany). Pearson product moment correlation was used for correlation analysis.

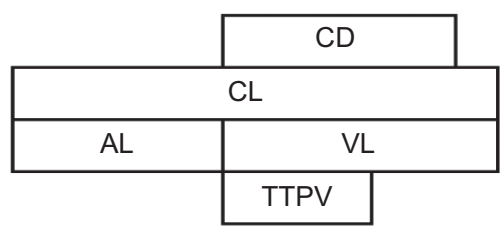

a)

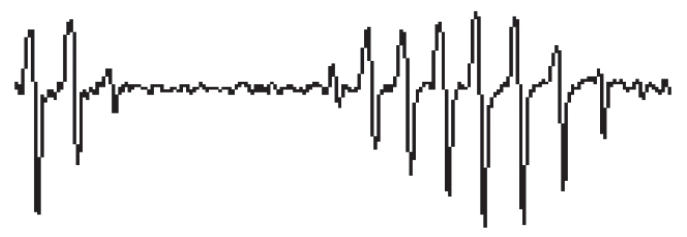

b)

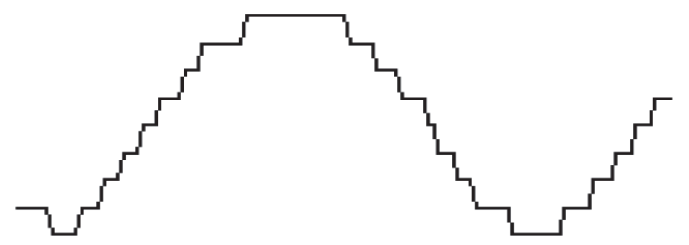

c)

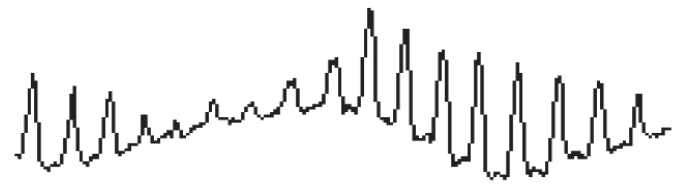

d)

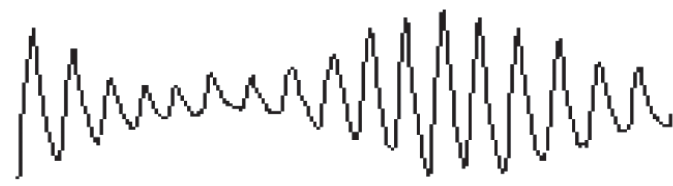

FIGURE 1. Scheme of respiratory event lengths a) nasal airflow, b) peripheral oxygen staturation, c) chest effort, and d) abdominal effort in obstructive sleep apnoea. CD: circulatory delay; CL: cycle length; AL: apnoea length; VL: ventilation length; TTPV: time to peak ventilation. 
Differences between groups were analysed using MannWhitney rank sum test, t-test or Fisher's exact test. A value of $\mathrm{p}<0.05$ was considered statistically significant.

\section{RESULTS}

\section{Patient characteristics}

Demographic and clinical parameters for the 39 patients included in the study are shown in table 1. Other than OSA patients with heart failure $(n=26)$ being younger, and baseline parameters used as inclusion criteria (LVEF, NT-proBNP), there were no differences between groups in baseline parameters.

\section{Haemodynamic parameters}

While cardiac index and aortic oxygen saturation were not statistically different between the two patient groups, those with heart failure had elevated mean arterial pressure, mean pulmonary artery pressure and mean pulmonary capillary wedge pressure (PCWP), and lower mixed venous oxygen saturation compared with patients without heart failure (table 2).

\section{Respiratory parameters}

The total AHI and obstructive apnoea index were comparable in both groups. There were no differences between those with and without heart failure in mean oxygen desaturations at night (table 2). All measured respiratory parameters were prolonged in patients with heart failure versus without heart failure: CL $37.8 \pm 10.6 \mathrm{~s}$ versus $46.0 \pm 10.0 \mathrm{~s}, \mathrm{p}=0.024 ; \mathrm{VL} 21.3 \pm 7.1 \mathrm{~s}$ versus $25.4 \pm 6.3 \mathrm{~s}, \mathrm{p}=0.044 ;$ AL $16.5 \pm 3.9 \mathrm{~s}$ versus $20.5 \pm 4.9 \mathrm{~s}, \mathrm{p}=0.013$; TTPV $8.3 \pm 2.5 \mathrm{~s}$ versus $10.6 \pm 3.0 \mathrm{~s}, \mathrm{p}=0.021$ and CD $22.6 \pm 3.7 \mathrm{~s}$ versus $28.5 \pm 7.5 \mathrm{~s}, \mathrm{p}=0.005$ (fig. 2 ).

Statistically significant correlations between $\mathrm{CD}$ and $\mathrm{CL}$ $(\mathrm{r}=0.531, \mathrm{p}=0.005), \mathrm{VL} \quad \mathrm{r}=0.503, \mathrm{p}=0.009), \mathrm{AL} \quad(\mathrm{r}=0.434$, $\mathrm{p}=0.027)$ and TTPV $(\mathrm{r}=0.576, \mathrm{p}=0.002)$ were documented in patients with OSA and heart failure (OSA with heart failure); with increase in $\mathrm{CD}$, respiratory event lengths prolonged (fig. 3). Correlations between AL and the following ventilation

\section{TABLE 1 Demographic and clinical parameters}

\begin{tabular}{|c|c|c|c|}
\hline & OSA without heart failure ${ }^{\#}$ & OSA with heart failure & p-value \\
\hline Subjects $\mathrm{n}$ & 13 & 26 & \\
\hline Male & 6 & 18 & NS \\
\hline $\mathrm{BMI} \mathbf{k g} \cdot \mathrm{m}^{-2}$ & $31.7 \pm 6.6$ & $30.6 \pm 4.6$ & NS \\
\hline NYHA class & $2.5 \pm 0.5$ & $2.7 \pm 0.5$ & NS \\
\hline$f_{c}$ beats $\cdot \mathrm{min}^{-1}$ & $70 \pm 8$ & $71 \pm 11$ & NS \\
\hline LVEF \% & $55 \pm 1$ & $32 \pm 6$ & $<0.001$ \\
\hline \multicolumn{4}{|l|}{ Medication } \\
\hline ACEI/ARB & 77 & 96 & NS \\
\hline Diuretics & 38 & 92 & $<0.001$ \\
\hline Statins & 38 & 38 & NS \\
\hline \multicolumn{4}{|l|}{$\mathrm{CV}$ risk factors } \\
\hline CAD & 38 & 58 & NS \\
\hline Hypertension & 85 & 73 & NS \\
\hline Diabetes & 23 & 27 & NS \\
\hline \multicolumn{4}{|l|}{ Smoking } \\
\hline Current & 15 & 8 & NS \\
\hline Former & 23 & 38 & NS \\
\hline \multicolumn{4}{|l|}{ Laboratory findings } \\
\hline NT-proBNP pg $\cdot \mathrm{mL}^{-1}$ & $167 \pm 106$ & $1999 \pm 1696$ & $<0.001$ \\
\hline Haemoglobin $\mathrm{g} \cdot \mathrm{dL}^{-1}$ & $14.0 \pm 1.3$ & $13.5 \pm 1.6$ & NS \\
\hline
\end{tabular}

Data are presented as mean \pm SD or \%, unless otherwise stated. OSA: obstructive sleep apnoea; BMI: body mass index; NYHA: New York Heart Association; BP: blood pressure; fc: cardiac frequency; LVEF: left ventricular ejection fraction; ACEl: angiotensin converting enzyme inhibitor; ARB: angiotensin receptor blocker; CV: cardiovascular; CAD: coronary artery disease; NT-proBNP: N-terminal pro-brain natriuretic peptide; hsCRP: high-sensitivity C-reactive protein; NS: not significant. ${ }^{*}$ : LVEF $\geqslant 50 \%$, NT-proBNP $<400 \mathrm{pg} \cdot \mathrm{mL}^{-1}$; ${ }^{\bullet}$ : obstructive sleep apnoea with heart failure (NYHA class II and III, LVEF $\leqslant 40 \%$ ). 
TABLE 2 Haemodynamic and respiratory results

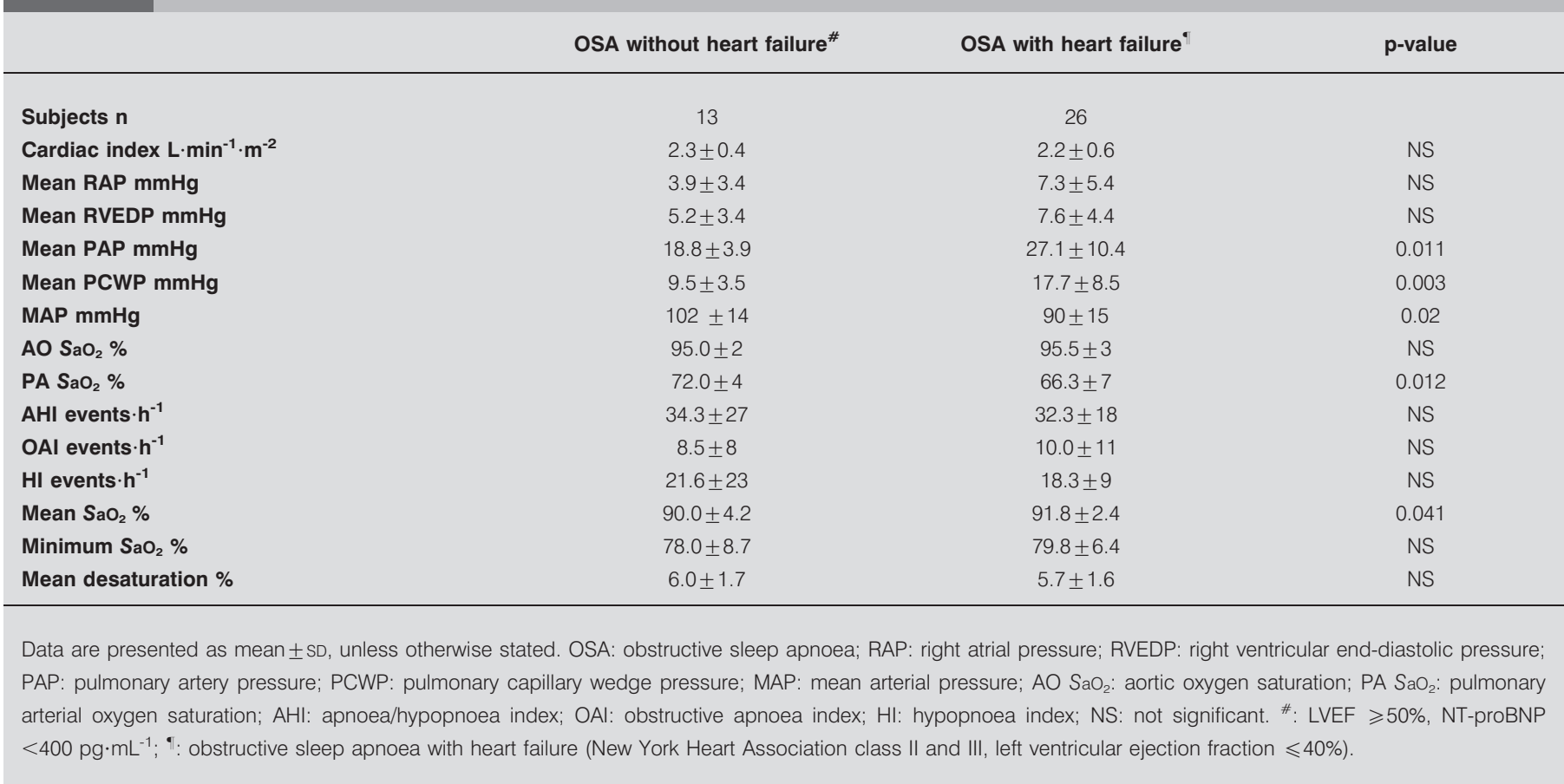

period (VL) were significant in both patient groups (OSA without heart failure, $r=0.863, p<0.001$; OSA with heart failure, $\mathrm{r}=0.581, \mathrm{p}=0.002)$; as apnoea duration increased, the following ventilation time was prolonged (fig. 4).
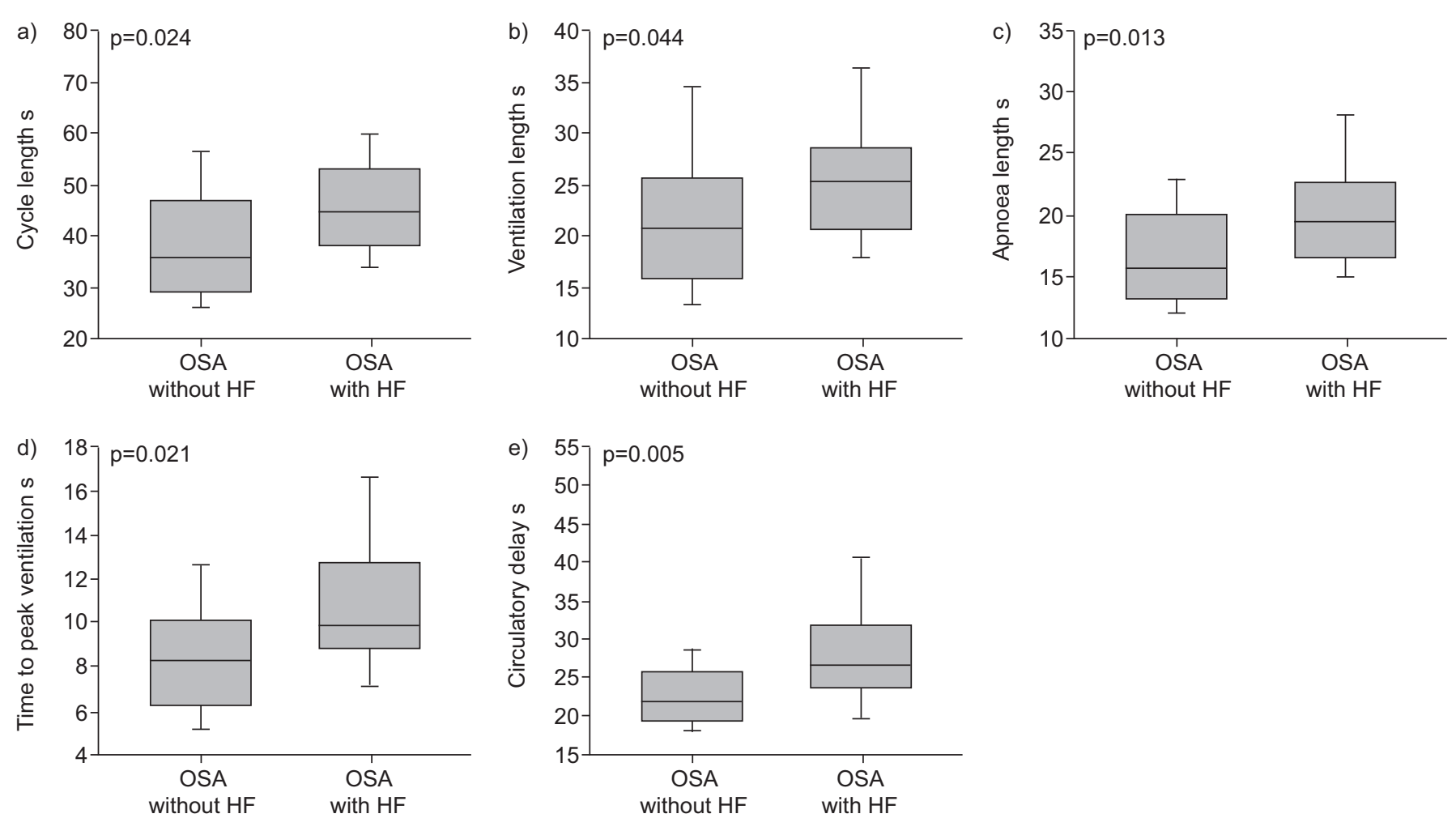

\section{Correlation between haemodynamic and respiratory parameters}

There were no correlations between left ventricular function and respiratory parameters in OSA patients without heart

FIGURE 2. Differences in a) cycle length, b) ventilation length, c) apnoea length, d) time to peak ventilation and e) circulatory delay between obstructive sleep apnoea (OSA) patients with heart failure (HF) and without HF. 

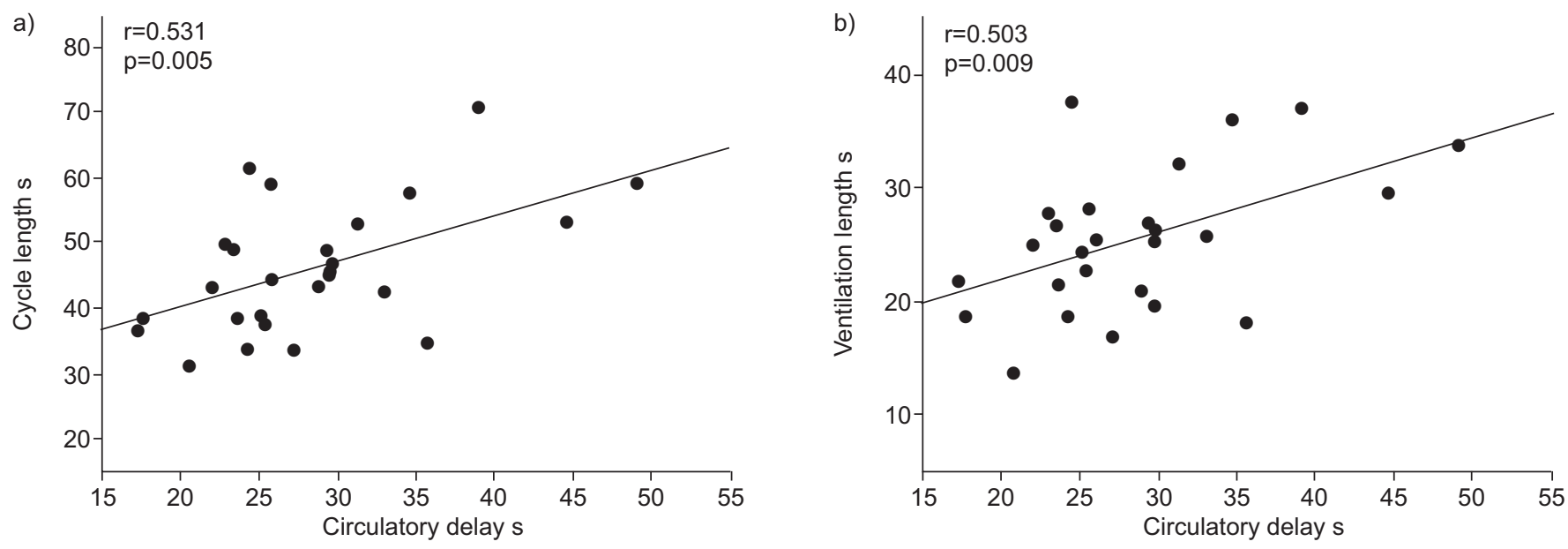

FIGURE 3. Correlations between circulatory delay and a) cycle length or b) ventilation length in obstructive sleep apnoea patients with heart failure.

failure. In contrast, significant and robust correlations between respiratory and haemodynamic parameters were documented in OSA patients with heart failure; CL, VL and TTPV increased as pulmonary congestion (PCWP) worsened: CL $\mathrm{r}=0.53$, $\mathrm{p}=0.006 ; \mathrm{VL} \mathrm{r}=0.55, \mathrm{p}=0.004$; and TTPV $\mathrm{r}=0.47, \mathrm{p}=0.015$ (fig. 5). Correlations between PCWP and AL $(r=0.37, p=0.63)$ or $\mathrm{CD}(\mathrm{r}=0.36, \mathrm{p}=0.072)$ were not statistically significant.

\section{DISCUSSION}

The main findings of this study were a difference in OSArelated respiratory patterns (respiratory event lengths) in patients with and without heart failure, and a significant positive correlation between pulmonary congestion and respiratory event lengths in OSA patients with heart failure.

In general, respiratory event lengths were prolonged in heart failure patients compared with OSA patients without subjective and objective signs of heart failure. These differences in OSA respiratory patterns between patients with and without heart failure are consistent with the findings of RYAN et al. [18] who investigated respiratory event lengths in 40 OSA patients with $(n=22)$ or without $(n=18)$ heart failure. However, the

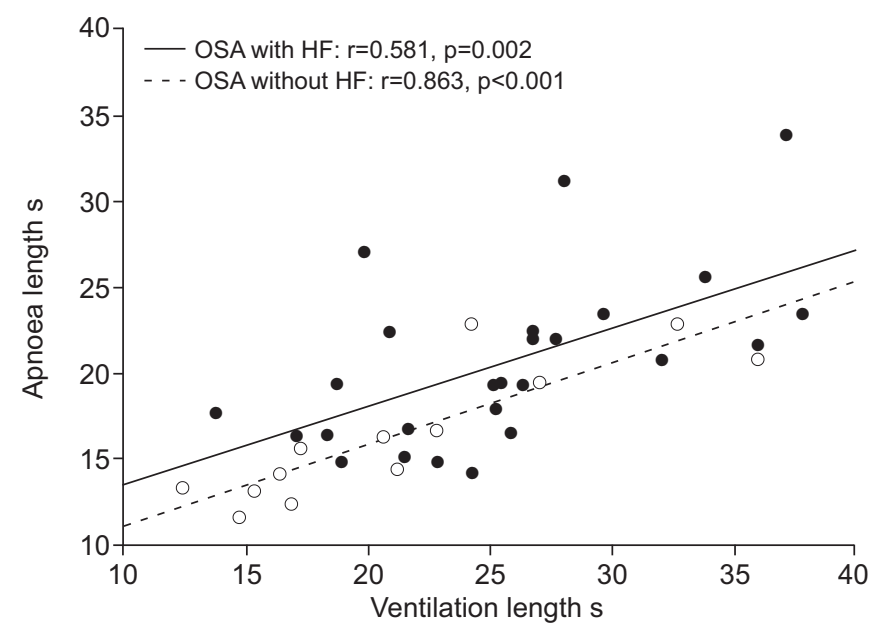

FIGURE 4. Correlations between ventilation lengths and apnoea lengths. OSA: obstructive sleep apnoea; HF: heart failure. correlations between $\mathrm{CD}$ and other respiratory event lengths identified in our trial go beyond the results of the previous study [18]. With deterioration of cardiac function, as indicated by a lengthening in $C D$, respiratory event lengths such as $C L$, VL, AL and TTPV were prolonged. Two other studies have reported different respiratory patterns in the presence and absence of heart failure in patients with CSA [17, 19].

Heart failure itself is associated with an increase in circulation time and, in the context of apnoeas, with an increase in CD. Our results showed a progressive delay, with an increase in peripheral oxygen exhaustion indicated by lower mixed venous saturation.

The correlation between prolonged CD and TTPV as well as VL can be explained by the dynamic response to asphyxia in OSA patients [22] and the finding that CD results in hyperventilation [23]. The amplified response of peripheral chemoreceptors to a high carbon dioxide level causes hyperventilation. In patients without SDB, the response of peripheral chemoreceptors to changes in blood gas tensions may not be as dynamic as that in patients with CSA or OSA.

The current study showed that a longer VL is associated with a comparable lengthening of AL. This correlation between VL and AL may be interpreted in two different ways. First, it might be due to changes in chemical control in OSA patients. The results of two previous studies showed that patients with untreated OSA have greater ventilatory instability and therefore a higher AHI $[24,25]$. The chemical control system might be unstable in patients with OSA, probably because of altered sensitivity in the feedback loop (loop gain). Alternatively, the explanation may be the prolonged circulation time and higher carbon dioxide levels in heart failure patients. The longer circulation time leads to a delayed report of gas tensions and this contributes to a longer AL with associated increases in carbon dioxide levels and a prolonged time until reaching the apnoea threshold. A longer AL causes a longer VL, without a change in loop gain.

Another important finding of this study was documentation of a correlation between pulmonary congestion and respiratory event lengths. This is the first time that an interaction between 

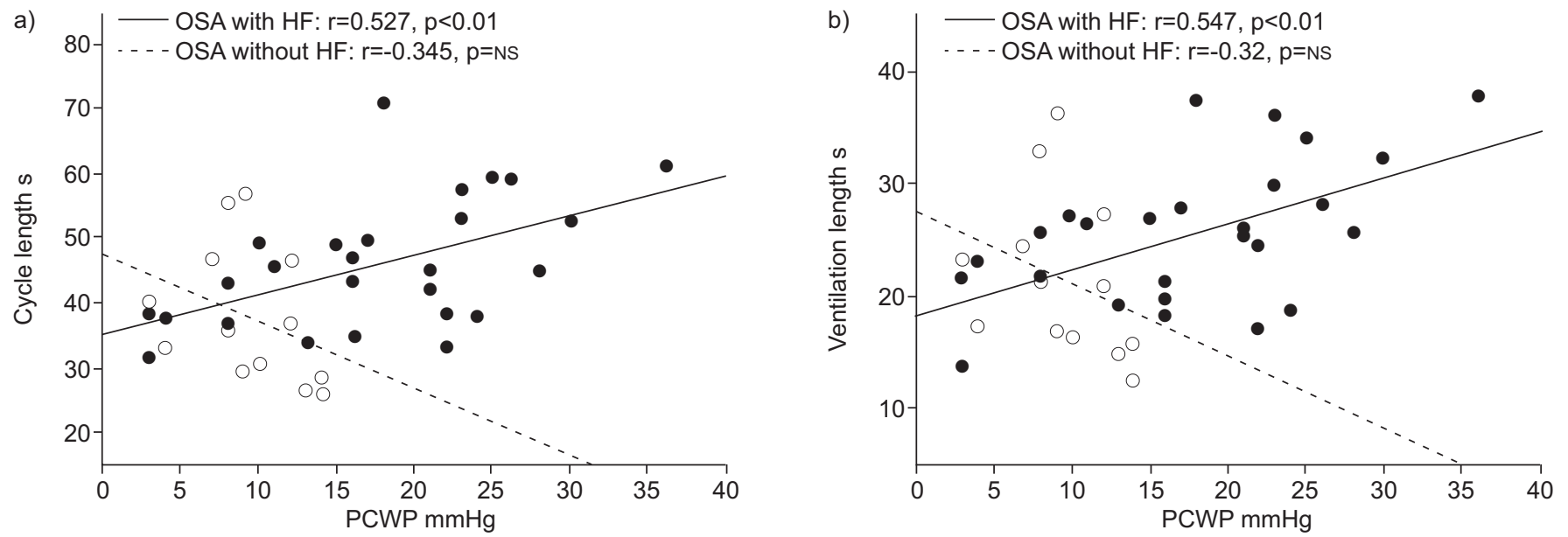

FIGURE 5. Correlations between pulmonary congestion (pulmonary capillary wedge pressure; PCWP) and respiratory event lengths. OSA: obstructive sleep apnoea; HF: heart failure; NS: not significant.

heart failure severity and respiratory patterns in OSA has been reported. Despite these results, we were unable to demonstrate any correlations between PCWP and AHI, obstructive apnoea index or hypopnoea index. An earlier study by our group also showed no correlations between PCWP or pulmonary artery pressure and $\mathrm{AHI}$, apnoea index or obstructive apnoea index in OSA patients (AHI $>5$ events $\cdot h^{-1}$ ) with heart failure [26]. In contrast, there were correlations between all these parameters for heart failure patients with CSA. Respiratory event lengths were not investigated. A correlation between PCWP and AHI was detected in 33 additional patients with CSA and heart failure [15].

Taken together, these results call the suitability of $\mathrm{AHI}$ as a marker of SDB severity into question. In heart failure patients, respiratory event lengths may provide a more precise estimate of disease severity in OSA. Furthermore, the conclusion that OSA is not dependent on heart failure severity is potentially unreliable [26].

In a recent study, JAFARI and MOHSENIN [10] confirmed a fluid shift from the periphery towards the neck in patients with OSA. Because the AHI did not change, they concluded that this rostral fluid shift had no significant impact on the severity of OSA. Our previous [26] and current results show that AHI is not a good measure of OSA severity, at least in patients with heart failure. Routine measurements of respiratory event lengths could provide more insight into severity of SDB, regardless of whether the aetiology is primarily obstructive or central.

The potential for heart failure to have an influence on OSA severity was shown in this study. Patterns of OSA depend on the degree of pulmonary congestion. Two other studies have also discussed links between OSA and heart failure. CIOFFI et al. [27] investigated the prevalence of left ventricular systolic dysfunction and OSA in 300 patients. Left ventricular systolic dysfunction was significantly more prevalent in patients with OSA of any severity compared with those who did not have SDB. Although these results do not provide causative evidence, they do indicate a relationship of some sort. It has also been shown that OSA can impair left ventricular diastolic function, irrespective of other possible factors [28]. In combination, the findings of these different studies highlight the presence of a reciprocal relationship between OSA and heart failure.

Male sex also appears to be an independent risk factor for the development of OSA in younger adults [29, 30]. The results of the current study agree with these previous findings, with the group of patients having heart failure and OSA being significantly younger and more likely to be male than those who have OSA without heart failure.

There are a number of limitations of this study. Multi-channel cardiorespiratory polygraphy recordings were used and no polysomnography was performed. Therefore, data on sleep, sleep quality and arousals are not available. This means that total AHI could be underestimated because total sleep time might be shorter than total recording time. In addition, because we could not detect arousal, hypopnoea scoring was only possible using airflow and oxygen saturation data. Nevertheless, for the purpose of measuring obstructive respiratory patterns, high quality polygraphy recordings provide all the important information required. We tried to perform polygraphy studies as closely as possible to the time of invasive haemodynamic measurements. It is probably not feasible to perform a full polysomnography study in a sleep laboratory while a patient is awaiting or has just had cardiac catheterisation. The small sample size is another limiting factor. Inclusion of 39 patients means that our study is similar to previous trials, but multivariate analysis is not possible with this number of patients and potential confounding factors cannot be definitely ruled out. Therefore, further studies are required to more fully and accurately determine respiratory event lengths in patients with OSA and heart failure. Finally, (longitudinal) follow-up studies are required to investigate a potential dependency of respiratory event lengths and other respiratory or SDB parameters on cardiac function. How these parameters (type of SDB, graduation, event lengths, etc.) might change with deterioration or recovery of cardiac function is unclear and needs to be determined. This might open a possibility to monitor cardiac function in heart failure patients. 


\section{Conclusions}

We have shown that respiratory patterns in OSA are dependent on cardiac function. Impaired cardiac function is associated with an increase in respiratory event lengths. In patients with heart failure, some of these events correlate with the degree of pulmonary congestion. In light of these results, the AHI does not appear to be a good measure of SDB severity and respiratory impairment in patients with OSA and heart failure.

\section{STATEMENT OF INTEREST}

Conflict of interest information can be found alongside the online version of this article at www.erj.ersjournals.com

\section{REFERENCES}

1 Gottlieb DJ, Yenokyan G, Newman AB, et al. Prospective study of obstructive sleep apnea and incident coronary heart disease and heart failure: the Sleep Heart Health Study. Circulation 2010; 122: 352-360.

2 Bitter T, Westerheide N, Prinz C, et al. Cheyne-Stokes respiration and obstructive sleep apnoea are independent risk factors for malignant ventricular arrhythmias requiring appropriate cardioverterdefibrillator therapies in patients with congestive heart failure. Eur Heart J 2011; 32: 61-74.

3 Wang H, Parker JD, Newton GE, et al. Influence of obstructive sleep apnea on mortality in patients with heart failure. J Am Coll Cardiol 2007; 49: 1625-1631.

4 Kasai T, Narui K, Dohi T, et al. Prognosis of patients with heart failure and obstructive sleep apnea treated with continuous positive airway pressure. Chest 2008; 133: 690-696.

5 Oldenburg O, Lamp B, Faber L, et al. Sleep-disordered breathing in patients with symptomatic heart failure: a contemporary study of prevalence in and characteristics of 700 patients. Eur J Heart Fail 2007; 9: 251-257.

6 Sin DD, Fitzgerald F, Parker JD, et al. Risk factors for central and obstructive sleep apnea in 450 men and women with congestive heart failure. Am J Respir Crit Care Med 1999; 160: 1101-1106.

7 Schulz R, Blau A, Borgel J, et al. Sleep apnoea in heart failure. Eur Respir J 2007; 29: 1201-1205.

8 White DP. Pathogenesis of obstructive and central sleep apnea. Am J Respir Crit Care Med 2005; 172: 1363-1370.

9 Lin CM, Davidson TM, Ancoli-Israel S. Gender differences in obstructive sleep apnea and treatment implications. Sleep Med Rev 2008; 12: 481-496.

10 Jafari B, Mohsenin V. Overnight rostral fluid shift in obstructive sleep apnea: does it affect the severity of sleep-disordered breathing? Chest 2011; 140: 991-997.

11 Wellman A, Eckert DJ, Jordan AS, et al. A method for measuring and modeling the physiological traits causing obstructive sleep apnea. J Appl Physiol 2011; 110: 1627-1637.

12 Yumino D, Redolfi S, Ruttanaumpawan P, et al. Nocturnal rostral fluid shift: a unifying concept for the pathogenesis of obstructive and central sleep apnea in men with heart failure. Circulation 2010; 121: 1598-1605.

13 Oldenburg $\mathrm{O}$, Faber L, Vogt J, et al. Influence of cardiac resynchronisation therapy on different types of sleep disordered breathing. Eur J Heart Fail 2007; 9: 820-826.
14 Wedewardt J, Bitter T, Prinz C, et al. Cheyne Stokes respiration in heart failure: cycle length is dependent on left ventricular ejection fraction. Sleep Med 2010; 11: 137-142.

15 Solin $\mathrm{P}$, Bergin $\mathrm{P}$, Richardson $\mathrm{M}$, et al. Influence of pulmonary capillary wedge pressure on central apnea in heart failure. Circulation 1999; 99: 1574-1579.

16 Sinha A, Skobel EC, Breithardt O, et al. Cardiac resychronization therapy improves central sleep apnea and Cheyne-Stokes respiration in patients with chronic heart failure. J Am Coll Cardiol 2004; 44: 68-71.

17 Hall M, Xie A, Rutherford R, et al. Cycle length of periodic breathing in patients with and without heart failure. Am J Respir Crit Care Med 1996; 154: 376-381.

18 Ryan CM, Bradley TD. Periodicity of obstructive sleep apnea in patients with and without heart failure. Chest 2005; 127: 536-542.

19 Solin P, Roebuck T, Swieca J, et al. Effects of cardiac dysfunction on non-hypercapnic central sleep apnea. Chest 1998; 113: 104-110.

20 Dickstein K, Cohen-Solal A, Filippatos G, et al. ESC Guidelines for the diagnosis and treatment of acute and chronic heart failure 2008: the Task Force for the Diagnosis and Treatment of Acute and Chronic Heart Failure 2008 of the European Society of Cardiology. Developed in collaboration with the Heart Failure Association of the ESC (HFA) and endorsed by the European Society of Intensive Care Medicine (ESICM). Eur Heart J 2008; 29: 2388-2442.

21 Iber C, Ancoli-Israel S, Chesson A, et al. The AASM Manual for the Scoring of Sleep and Associated Events: Rules, Terminology and Technical Specifications, 1st Edn. Westchester, American Academy of Sleep Medicine, 2007.

22 Loewen A, Ostrowski M, Laprairie J, et al. Determinants of ventilatory instability in obstructive sleep apnea: inherent or acquired? Sleep 2009; 32: 1355-1365.

23 Younes M, Ostrowski M, Atkar R, et al. Mechanisms of breathing instability in patients with obstructive sleep apnea. J Appl Physiol 2007; 103: 1929-1941.

24 Wellman A. Ventilatory control and airway anatomy in obstructive sleep apnea. Am J Respir Crit Care Med 2004; 170: 1225-1232.

25 Younes M, Ostrowski M, Thompson W, et al. Chemical control stability in patients with obstructive sleep apnea. Am J Respir Crit Care Med 2001; 163: 1181-1190.

26 Oldenburg O, Bitter T, Wiemer M, et al. Pulmonary capillary wedge pressure and pulmonary arterial pressure in heart failure patients with sleep-disordered breathing. Sleep Med 2009; 10: 726-730.

27 Cioffi G, Russo TE, Selmi A, et al. Analysis of left ventricular systolic function by midwall mechanics in patients with obstructive sleep apnoea. Eur J Echocardiogr 2011; 12: 61-68.

28 Arias MA. Obstructive sleep apnea syndrome affects left ventricular diastolic function: effects of nasal continuous positive airway pressure in men. Circulation 2005; 112: 375-383.

29 Young T, Palta M, Dempsey JA, et al. The occurence of sleepdisordered breathing among middle-aged adults. New Engl J Med 1993; 328: 1230-1235.

30 Woehrle $\mathrm{H}$, Arzt $\mathrm{M}$, Oldenburg $\mathrm{O}$, et al. Prädiktoren für schlafbezogene Atmungsstörungen bei Patienten mit stabiler chronischer Herzinsuffizienz mit eingeschränkter linksventrikulärer Pumpfunktion. [Predictors of sleep-disordered breathing in patients with stable chronic heart failure with reduced left ventricular function]. Clin Res Cardiol 2012; 101: P1037. 